\title{
Psychotherapy for child and adolescent with psychiatric disorder attending in National Institute of Mental Health, Dhaka
}

\author{
Md Zahir Uddin, ${ }^{1}$ Muhammad Zillur Rahman Khan, ${ }^{2}$ Mumita Jerin Nilav, ${ }^{3}$ Md Faruq Alam, ${ }^{4}$ Md Abdul Mohit ${ }^{5}$ \\ ${ }^{1}$ Assistant Professor of Clinical Psychology, Department of Psychotherapy, National Institute of Mental Health \\ (NIMH), Sher-E-Bangla Nagar, Dhaka, Bangladesh; ${ }^{2}$ Assistant Professor, Department of Child, Adolescent and \\ Family Psychiatry, NIMH, Dhaka, Bangladesh; ${ }^{3}$ MPhil Student, Department of Clinical Psychology, Dhaka \\ University, Dhaka, Bangladesh; ${ }^{4}$ Professor, Department of Child, Adolescent and Family Psychiatry, NIMH, Dhaka, \\ Bangladesh; 5Professor, Department of Psychotherapy, NIMH, Dhaka, Bangladesh.
}

\begin{tabular}{|c|c|}
\hline Article info & Summary: \\
\hline Received: 17 May 2016 & Psychotherapy for child and adolescent with psychiatric disorder is relatively a newer \\
\hline Accepted : 15 Aug 2016 & concept in Bangladesh. This cross sectional study was done to determine the pattern of \\
\hline Number of tables : 04 & $\begin{array}{l}\text { psychotherapy provided by the psychotherapy department for children and adolescents with } \\
\text { psychiatric disorder in National Institute of Mental Health (NIMH) from June } 2010 \text { to }\end{array}$ \\
\hline Number of figures : 03 & November 2014. Total 121 samples were taken purposefully from the records of \\
\hline Number of refs. : 12 & $\begin{array}{l}\text { Results showed that among respondents more were boys than girls }(64.5 \% \text { vs. } 35.5 \%) \\
\text { whereas their mean }( \pm S D) \text { age was } 12.1( \pm 3.2) \text { years. Majority }(47.9 \%) \text { of them were within } \\
\text { class six to class ten. Most of the respondents }(89 \%) \text { were referred from the outpatient } \\
\text { department and } 11 \% \text { were referred by inpatient department. Conduct disorder }(27.3 \%) \text {, } \\
\text { conversion disorder }(13.2 \%) \text {, attention deficit hyperactivity disorder }(12.4 \%) \text { and intellectual }\end{array}$ \\
\hline $\begin{array}{l}\text { Md Zahir Uddin } \\
\text { E-mail: } \\
\text { zahirm_bd@yahoo.com }\end{array}$ & $\begin{array}{l}\text { developmental disorder }(9.1 \%) \text { were common diagnoses of the respondents. It was found } \\
\text { that } 74.4 \% \text { respondents attended up to one to five psychotherapy sessions and cognitive } \\
\text { behavior therapy (38\%) and behavior therapy (25.6\%) were most commonly used } \\
\text { psychotherapy. Though } 60.3 \% \text { of the respondents improved to certain extent in } \\
\text { psychotherapy sessions, patient's dropout rate was found as } 55.4 \% \text {. }\end{array}$ \\
\hline
\end{tabular}

Bang J Psychiatry 2014,28(2):53-57

\section{Introduction}

Prevalence of DSM-IV mental disorder, mental retardation, epilepsy and substance related disorder was $18.4 \%, 3.8 \%$, 2.0 and $0.8 \%$ respectively among children of Dhaka division, Bangladesh. ${ }^{1,2}$ Psychiatric service has been available in Bangladesh for around fifty years. 'Psychotherapy, Clinical Psychology and Psychiatric Social Work Department' (in brief Psychotherapy Department) started in the end of 2003 at National Institute of Mental Health (NIMH), Dhaka, Bangladesh. Since then, the department has been conducting psychotherapy for the patients.

"Psychotherapy is the informed and intentional application of clinical methods and interpersonal stances derived from established psychological principles for the purpose of assisting people to modify their behaviors, cognitions, emotions, and or other personal characteristics in directions that the participant deems desirable". ${ }^{3}$ In current study, by the term 'psychotherapy', it is meant all sorts of psychological treatment other than psychoanalysis.

A study done on adult patients at NIMH suggested that Cognitive Behavior Therapy was one of the effective modes of treatment for patients suffering from depressive illness and neurotic disorders. ${ }^{4}$ But research regarding psychotherapy especially with child psychiatric patients is very limited in Bangladesh. Taking this fact on consideration, the current study was conducted with an aim to describe the pattern of psychotherapy provided by the psychotherapy department for child and adolescent with psychiatric disorder at National Institute of Mental Health. The study also described the pattern of psychiatric disorder among the respondents, sociodemographic information of the patients and types of psychotherapy provided by the department. This was a baseline study which might provide a glimpse to policy makers about the pattern of psychotherapy among child population as well as to stimulate further study.

\section{Materials and methods}

This was a descriptive cross sectional study done from June 2010 to November 2014 in the 'Psychotherapy, Clinical Psychology and Psychiatric Social Work Department' in National Institute of Mental Health (NIMH), Dhaka, Bangladesh. Total 121 samples were taken conveniently from the records of psychotherapy 
department meeting the inclusion and exclusion criteria. Patients recorded of both sexes aged from 5-17 years and whose diagnoses was mentioned in the records as per Diagnostic and Statistical Manual of Mental Disorders $-4^{\text {th }}$ edition (DSM-IV) criteria were only included.' Using check list data were collected retrospectively from the records of Psychotherapy Department. During collection of data, if any patient was mentioned in the record of more than one diagnosis, only primary diagnosis was taken during data collection. Data analysis was done by the software Statistical Package for Social Sciences (SPSS) for windows-20 ${ }^{\text {th }}$ version. Frequency distribution, summary tables and appropriate graphs were used for presentation of the results. Ethical consideration was maintained throughout the study period and data were taken anonymously.

\section{Results}

Demographic information of the respondents showed that among the respondents, boys $(64.5 \%)$ were more in number than girls (35.5\%). Mean age of the respondents were $12.1(\mathrm{SD} \pm 3.2)$ years, minimum age was 5 years and maximum was 17 years. Major portions $(47.9 \%)$ of them were in class $\mathrm{VI}$ to class $\mathrm{X}$ (table 1). It was found that $89 \%$ respondents were referred by Out Patient Department (OPD) of NIMH and $11 \%$ was referred by inpatient department (figure 1). Conduct disorder $(27.3 \%)$, attention deficit hyperactivity disorder (12.4\%) and functional neurological symptom disorder. conversion disorder (13.2\%) were most common diagnoses among respondents (Figure 2). Most of them (74.4\%) attended one to five psychotherapy sessions (Table 2and mean (:SD) participation was $4.5 \quad$ (SD: 4.8) persons. Cognitive-behavior therapy (38.0\%) and behavior therapy (25.6\%)were mostly administered on the respondents (Table 3). On an average 5.1 parents of children with child psychiatric disorders attended in parenting training group session during this period. Altogether, 14 sessions conduced. Drop out from the psychotherapy was $55.4 \%$ (Figure 3) and 60.3\% respondents got improvement to some extent (Table 4).

Table 1: Demographic characteristics of the respondents ( $n=121)$

\begin{tabular}{llcc}
\hline \multicolumn{2}{l}{ Characteristics } & Frequency & Percentage(\%) \\
\hline Sex & Boy & 78 & 64.5 \\
& Girl & 43 & 35.5 \\
Age & $5-9$ & 24 & 19.8 \\
& $10-14$ & 68 & 56.2 \\
\multirow{4}{*}{ Education } & $15-18$ & 29 & 24.0 \\
& Class I-V & 41 & 33.9 \\
& Class VI-X & 58 & 47.9 \\
& SSC \& above & 6 & 5.0 \\
\hline
\end{tabular}

Mean age of the respondents was $12.1(\mathrm{SD} \pm 3.2)$ years with a range of 5-17 years.

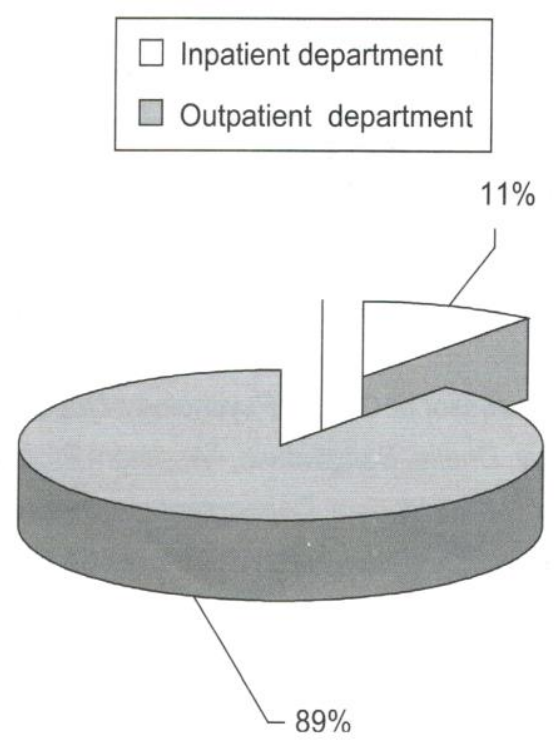

Figure 1: Sources of referral of the respondents $(n=121)$

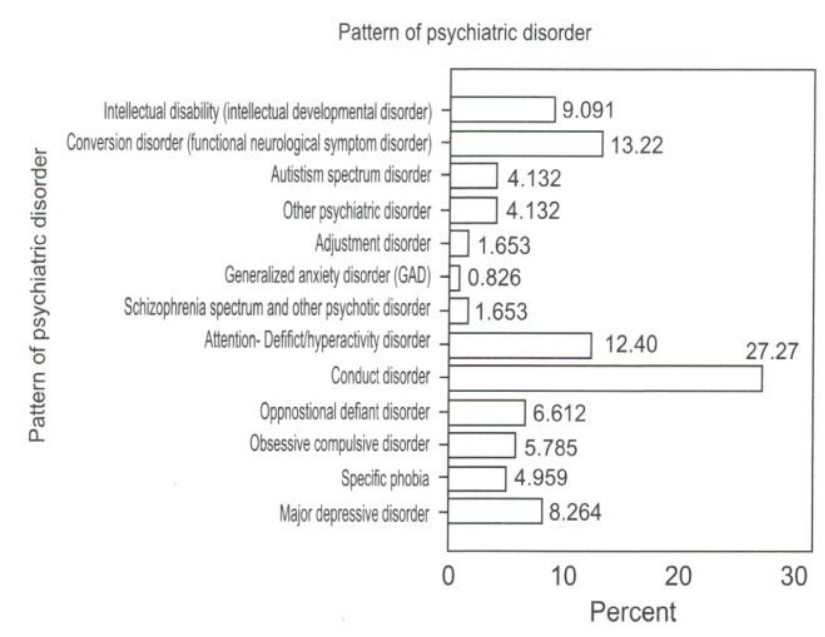

Figure 2: Pattern of psychiatric disorders of the respondents $(n=121)$

Table 2: Number of sessions attended by the respondents $(n=121)$

\begin{tabular}{lcc}
\hline No. of sessions attended & Frequency & Percentage \\
\hline $1-5$ session & 90 & 74.4 \\
$6-10$ session & 23 & 19.0 \\
$11-15$ session & 5 & 4.1 \\
16 or more session & 3 & 2.5 \\
\hline
\end{tabular}

Mean session participation was $4.5(\mathrm{SD} \pm 4.8)$. Minimum participation in the session was 1 and maximum was 37 sessions. The figure showed that maximum patients $(74.4 \%)$ attended 1-5 psychotherapy sessions. 
Table 3: Types of psychotherapy given $(n=121)$

\begin{tabular}{lcc}
\hline Type of psychotherapy & Frequency & Percentage \\
\hline Cognitive behavior therapy & 46 & 38.0 \\
Behavior therapy & 31 & 25.6 \\
Creative therapy & 12 & 9.9 \\
Only assessment & 23 & 19.0 \\
Only psycho education & 9 & 7.4 \\
\hline
\end{tabular}

Cognitive behavior therapy (38\%) was most common mode of psychotherapy delivered to the respondents.

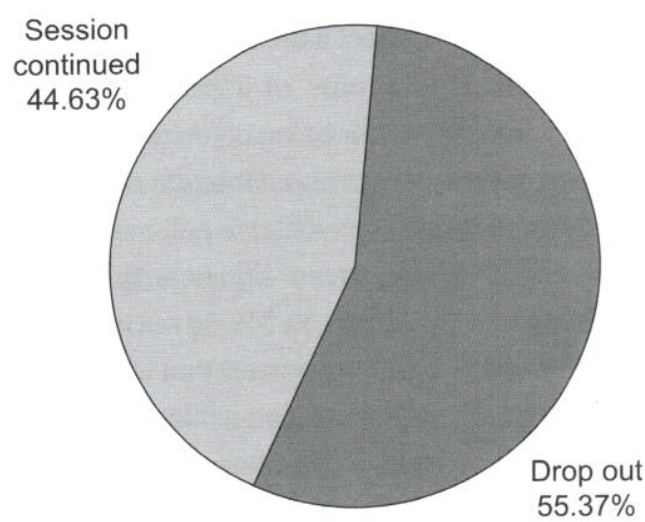

Figure 3: Drop out from the psychotherapy sessions by patients $(n=121)$

Table 4: Improvement of the respondents through psychotherapy session based on therapists' impression ( $n=121)$

\begin{tabular}{lcc}
\hline Level of improvement & Frequency & Percentage \\
\hline Not improved & 25 & 20.7 \\
Mildly improved & 26 & 21.5 \\
Moderately improved & 28 & 23.1 \\
Significantly improved & 19 & 15.7 \\
\hline
\end{tabular}

\section{Discussion}

According to current study, most common diagnosis among the respondents was conduct disorder (27.3\%), followed by conversion disorder/functional neurological symptom disorder (13.2\%), attention deficit hyperactivity disorder (12.4\%) and intellectual disability/ intellectual developmental disorder (9.1\%). Different rates found in a survey conducted in Dhaka division among children. Diagnoses found from most frequent were enuresis $(3.0 \%)$, somatoform pain disorder (2.0\%) and communication disorder (1.6\%). In that study, rate of conduct disorder $(1.0 \%)$, attention deficit hyperactivity disorder $(1.0 \%)$ and conversion disorder $(0.8 \%)$ and intellectual disability mental retardation $(3.8 \%)$ were much less. ${ }^{2} \mathrm{~A}$ hospital based study done in Child Guidance Clinic of NIMH showed that attention deficit hyperactive disorder $(27.09 \%)$, mental retardation (18\%) and autistic spectrum disorder (13.05\%) were common diagnoses. ${ }^{5}$ This result showed somehow similar results of current study as both of them were done in same hospital. But result of the population survey was somehow different. The difference might be due to difference in population.

Current study showed that maximum patients $(74.4 \%)$ attended 1-5 psychotherapy sessions (Table 2). Another study done on psychotherapy department at NIMH on adult psychiatric cases revealed that $82.9 \%$ patients attended one to five psychotherapy sessions. ${ }^{6}$ A foreign study suggested that the average number of sessions received in a national database of over 6,000 patients were less than five. The rate of improvement in this sample was only about $20 \%{ }^{7}$ Another study revealed that by 8 sessions approximately $50 \%$ of patients were measurably improved, and approximately $75 \%$ were improved by 26 sessions. $^{8}$ However, it is recommended to ensure attendance in psychotherapy session up to at least 26 or more sessions to ensure effective delivery of psychotherapy.

Here it was found that $38.0 \%, 25.6 \%$ and $9.9 \%$ respondents respectively received Cognitive Behavior Therapy (CBT), behavior therapy and creative therapy respectively. Another study conducted on adult psychiatric patients revealed that $49.2 \%, 11.2 \%$ and $11.2 \%$ respondents got cognitive-behavior therapy, behavior therapy and exploratory psychotherapy respectively as a mode of treatment. ${ }^{6}$ Cognitivebehavior therapy was widely used treatment method as revealed in current study. Cognitive behavior therapy is time limited; goal directed and focuses mainly on present time. That is why; CBT is widely used in all over the world. Moreover, patients normally are not used to continue psychotherapy sessions for long time in Bangladesh. CBT is a time limited therapy and thus quite handy to use in this country. For child and adolescents with psychiatric disorder, behavior problem is one of main factors of concern where behavior therapy has been proved quite useful. Usually parents administer behavioral techniques as per guide of psychologist. Interestingly exploratory psychotherapy was not used on child psychiatric cases though $13.2 \%$ of the respondents had conversion disorder. One possible explanation might be inadequate record keeping by the psychotherapy department. Current study was done on kept record of the department. Reason might be explained by the fact that exploratory psychotherapy was administered without adequate notes on clinical record files. Current study showed that no family therapy was being administered on the family of child psychiatric cases though logically there was need for family work. In psychotherapy department, no staff was allocated to keep record 
and no software was being used. Trainee clinical psychologists used to keep records in their clinical note. As a result, data were not well kept. Psychotherapy department should take proper steps to maintain its record. Moreover, the department should focus on family therapy and family work with child psychiatric patients of the department.

Psychotherapy department did not have adequate human resources but gets lots of child psychiatric clients. In order to ensure some support to the parents and thus support to the child cases, psychotherapy department organized weekly parenting training for primary care givers of child psychiatric patients in group. The session included education on parenting style, learning theory and role of reinforcement, operant and classical conditioning and how they produce problematic behavior, management of problematic behavior, education on common child psychiatric cases, education on medical and psychological management of child psychiatric cases and question answer session. Totally fourteen parenting training sessions done in group and average participation was 5.1. Might be due to lack of awareness, or lack of information, very few participated on the parenting training group. In future, psychotherapy department should take initiative to solve this problem.

Current study showed that drop-out rate among the child respondents who were seeking psychotherapy was 55.4\%. A Bangladeshi study done on adult psychiatric patients of same department at NIMH showed that dropout rate was $29.4 \%$. $^{6}$ A meta-analysis found that mean dropout rate was $46.9 \% .^{9}$ So, dropout rate as found in current study was not much higher than scenario of other studies. Reason for drop-out could be explained by the factors of distance from hospital, dearth of awareness of psychological treatment as well as less motivation among patients and care givers, lack of knowledge regarding psychotherapy for child psychiatric patients, lower socioeconomic condition, low level of education, lack of habit to maintain strict schedule etc. A meta-analysis showed that drop-out rate found to be more in African-American (and other minority), less-educated, and lower income groups. ${ }^{9}$ Another study showed that drop out patients trend to see their therapists more negatively (i.e., less warm, empathic and genuine) following intake than did non drop-outs. ${ }^{10}$ Few factors were found to predict dropping out in $100 \%, 83-88 \%$, and $60-75 \%$ of the relevant studies: (a) social isolation and/or un-affiliation, therapist attitudes and behavior, discrepancies between patient and therapist treatment expectations; (b) passiveaggressive behavior, family attitudes and behavior, motivation, behavioral and/or perceptual dependence, psychological mindedness and/or denial, symptom levels and symptom relief, socioeconomic status, sociopathic features, alcoholism and/or drug dependence; and (c) age, sex, and social stability. ${ }^{11}$ Another study showed that several factors related to family (e.g., socioeconomic disadvantage, adverse child-rearing practices), parent (e.g., stress, life events, history of antisocial behavior), and child functioning (e.g., severity and chronicity of antisocial behavior, lower IQ, peer relations) predicted premature termination from treatment. ${ }^{12}$ More studies should be conducted to identify the factors associated with drop out and to resolve the grave issue. Present study found that according to impression of the therapist, $15.7 \%$, 23.1\%, and $21.5 \%$ respondents improved significantly, moderately or mildly respectively. However, $20.7 \%$ patients did not improve and $19.0 \%$ patient's data regarding improvement was not available. These rates of improvement were just psychologist's judgment rather being objective. Still then, from the data we can get some idea about the rate of improvement. Another study done on adult psychiatric patients showed that $13.3 \%, 6.1 \%$ and $22.5 \%$ improved 'significantly', 'moderately' and 'slightly' respectively though $39.3 \%$ did not improve. ${ }^{6}$ From the result of this study it can be viewed that there is scope to improve service quality so that we can achieve better outcome from psychotherapy sessions. Number of sessions attended was poor among the respondents and their diagnosis was also found to be varied which might have negatively influenced on the outcome of the psychotherapy sessions. A study showed differential responsiveness for different diagnostic groups and for different outcome criteria. ${ }^{8}$

\section{Conclusion}

Current study was done on records of psychotherapy department which was not properly maintained. So the results were interpreted considering the missing data. Proper maintenance of the record is essential in this regard. Future studies should focus on causes of drop out and ways to improve continuation of therapy.

\section{References}

1. American Psychiatric Association. Diagnostic and statistical manual of mental disorders. 4th ed. Washington DC: American Psychiatric Association; 2000.

2. Rabbani MG, Alam MF, Ahmed HU, Sarkar M, Islam MS, Anwar N, et al. Prevalence of mental disorders, mental retardation, epilepsy and substance abuse in children. Bang J Psychiatry 2009;23(1):11-53.

3. Norcross JC. An eclectic definition of psychotherapy. In: Zeig JK, Munion WM, editors. San Francisco CA: Jossey-Bass; 1990.

4. Mohit M, Uddin MZ, Ahmed HU, Chowdhury M, Hossain M, Ali M, et al. Efficacy of psychotherapy in the treatment of depression and anxiety in patients attending National Institute of Mental Health, Dhaka. Journal of NIMH 2009;1:43-63. 
5. Sarkar M, Khan MZR, Rabbani MG, Alam MF, Firoz AHM, Alam MT, et al. Pattern of psychiatric morbidity among the children and adolescents attending child guidance clinic of National Institute of Mental Health (NIMH), Dhaka. Bang J Psychiatry 2008;22(1):121.

6. Uddin MZ, Alam MS, Mohit M, Akhter R, Rahman AM. Psychotherapy in National Institute of Mental Health. Bang J Psychiatry 201;25(2):52-62.

7. Hansen N, Lambert M, Forman E. The psychotherapy dose-response effect and its implications for treatment delivery services. Clin Psychol-Sci Pr 2002;9(3):329-43.

8. Howard, Kenneth I, Mark K, Krause, Merton S, Orlinsky, et al. The dose-effect relationship in psychotherapy. Am Psychol 1986;41(2):159-64.
9. Wierzbicki, Michael, Pekarik, Gene. A meta-analysis of psychotherapy drop-out. Prof Psychol Res $\mathrm{Pr}$ 1993;24(2):190-5.

10. Edward B. Predicting patient drop out in psychotherapy. Psychotherapy 1992;29(2):177-82.

11. Ba-ekeland, Frederick, Lundwall, Lawrence. Dropping out of treatment: a critical review. Psychol Bull 1975;82(5):738-83.

12. Kazdin, Alan E, Mazurick, Jennifer L. Dropping out of child psychotherapy: Distinguishing early and late dropouts over the course of treatment. J Consult Clin Psych 1994;62(5):1069-74. 